\title{
EL GENIO FEMENINO Y LA AUTORIDAD LITERARIA: "LUISA MOLINA" DE GERTRUDIS GÓMEZ DE AVELLANEDA
}

\section{María C. Albin*}

\section{RESUMEN}

Este trabajo estudia el artículo periodístico “Luisa Molina” (1857), como ejemplo de la contribución que hace Gertrudis Gómez de Avellaneda al desarrollo del ensayo hispanoamericano. Gómez de Avellaneda explora y revisa el concepto de genio literario y su relación con la creatividad femenina, a través de una poeta desconocida que representa la figura del genio femenino.

Palabras claves: Gertrudis Gómez de Avellaneda, Luisa Molina, literatura cubana, ensayo hispanoamericano, genio literario, género, escritoras del siglo 19, romanticismo.

\section{ABSTRACT}

This work studies the contribution of Gertrudis Gómez de Avellaneda to the development of the Spanish American essay through one of her journalistic articles: "Luisa Molina" (1857). By using an unknown $19^{\text {th }}$ century woman poet as an example of the female genius, Gómez de Avellaneda explores and revises the concept of genius as it relates to female creativity.

Keywords: Gertrudis Gómez de Avellaneda, Luisa Molina, Cuban Literature, Spanish American Essay, genius, gender, $19^{\text {th }}$ century woman authors, Romanticism.

Recibido: 06.05.2004. Aprobado: 30.10.2004.

*Doctora en Literatura por la Universidad de Yale (USA). Profesora del Departamento de Español y Portugués de la Universidad de Columbia en Nueva York. Es autora del libro Género, poesía y esfera pública. Gertrudis Gómez de Avellaneda y la tradición romántica (Madrid: Trotta, 2002).E-mail:rm938@columbia.edu 


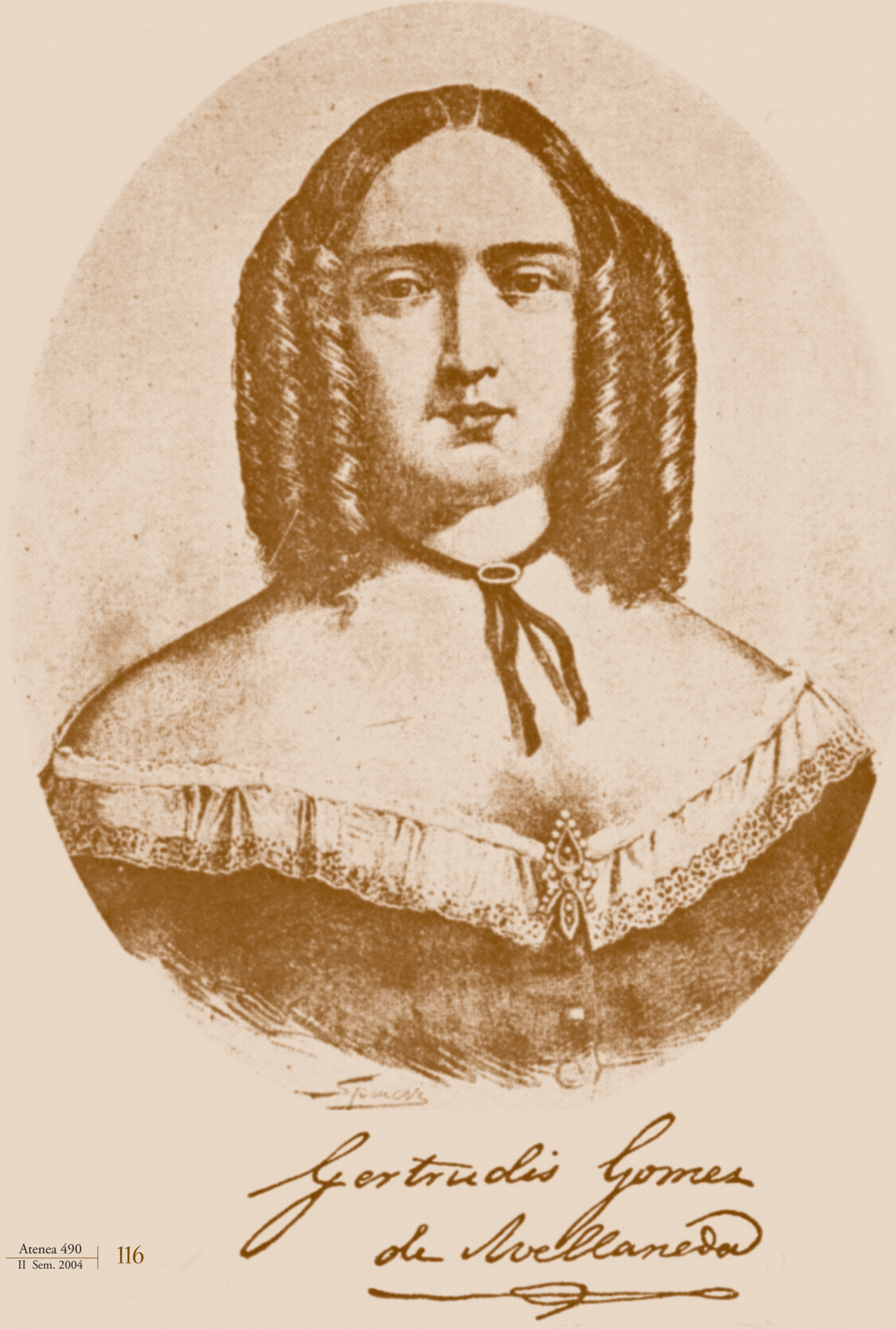


G ERTRUDIS Gómez de Avellaneda (1814-1873) fue una escritora prolífica que cultivó todos los géneros literarios. Sin embargo, existe una faceta de su extensa obra que aún no ha recibido la atención que merece: sus ensayos periodísticos. Los artículos de la escritora se distinguen por su densidad retórica, erudición y claridad en la exposición de las ideas, que por lo general se relacionan con el tema de la mujer. Por medio de estos escritos, Gómez de Avellaneda se nos revela como una destacada ensayista capaz de abordar el asunto que va a tratar desde la perpectiva de varias disciplinas, tales como la filosofía, la teología, la teoría política, la historia y la literatura. Con el objetivo de rescatar esta faceta de ensayista, dedicamos este trabajo a analizar el artículo periodístico "Luisa Molina" de Gertrudis Gómez de Avellaneda que aparece en el periódico La América, el 24 de mayo de 1857, y el cual representa una meditación sobre la posibilidad del genio femenino en las letras. La escritora aborda la cuestión de la genialidad femenina y discute el derecho para la mujer de talento de expresar su genio, a partir del comentario que hace en el artículo a la carta de Luisa Molina, una poeta campesina, cuya singular figura describe como "oscura, ignorada, humilde" (1857:9). En las primeras líneas con que da inicio al ensayo, Gómez de Avellaneda deja implícito que es necesario hacer salir de la oscuridad a los talentos femeninos, es decir, mostrarlos a la luz y darlos a conocer. La escritora intenta sacar a la figura y obra de su compatriota del aislamiento y ubicarla en el ámbito de la cultura pública, que es a la vez un lugar, el espacio público, y un acto que se traduce en la producción intelectual (Geneviè 1991: 27). El siguiente pasaje da comienzo al artículo:

No es una novela la que titulamos con el nombre desconocido que encabeza estas líneas: tampoco es una biografía; pues no vamos á ocuparnos, lo confesamos desde el principio, de ninguna de esas individualidades importantes que han sabido conquistarse poderosamente el interés del público... Dedicamos los cortos renglones, que hoy traza nuestra mano con emocion profunda, á una existencia... Que... no nos parece menos interesante... ni menos digna de simpatia que la celebridad mas pura (Gómez de Avellaneda 1857: 9).

El artículo periodístico de Gómez de Avellaneda se redacta como una respuesta a una carta de la escritora guajira que reproduce casi en su totalidad en el ensayo, y desde las primeras líneas adopta un tono epistolar cuando se dirige a Luisa Molina y le aconseja que no busque en "los pobres libros de los hombres" la fuente de su inspiración lírica, porque ella tiene a su disposición el inmenso libro de la naturaleza (1857: 10). Gómez de Avellaneda recurre a la metáfora del libro del universo, en la que todo el mundo visible se presenta ante los ojos del observador como un grande y maravilloso texto que contiene la sabiduría de su autor (Curtius 1990: 449). En su respuesta a Luisa Molina, la escritora asume una postura similar a la de Ni- 
colás de Cusa, quien recurre al ejemplo de un debate entre un letrado y un lego para demostrar que el último resulta ser más sabio debido a que obtiene su conocimiento de los libros de Dios y no de los libros de escuela (citado en Curtius 1990: 451). Por lo tanto, la poeta guajira posee una mayor sabiduría porque su conocimiento se deriva del libro de la naturaleza y no se basa exclusivamente ni en la razón teórica, ni en el pensamiento abstracto que contienen los textos escritos por los hombres. En un gesto retórico en que denuncia la exclusión de las mujeres del saber racional, Gómez de Avellaneda exhorta a la poeta campesina a que renuncie a la lectura de los libros materiales y se entregue de lleno al estudio del gran libro del mundo, superior a todos los demás, porque en su interior se esconde la sabiduría divina. A través del tópico del libro del universo, la escritora sugiere que el entendimiento poco refinado de Luisa Molina tiene más posibilidad de desarrollarse al contemplar los misterios del mundo sensible y asombrarse ante los milagros de la naturaleza; pues concluye que el verdadero conocimiento, esto es, la sabiduría eterna, no se encuentra en los textos impresos, sino en el gran libro del mundo que está constantemente frente a nuestros ojos y que tan sólo requiere de un observador atento.

La estrategia retórica que emplea la escritora es presentar, a través de la figura de la poeta campesina, una manera más positiva de imaginar la creatividad femenina en el mismo punto de su aparente exclusión y de liberar el potencial artístico de las mujeres. Es preciso tener en cuenta que existe una larga tradición que enfatiza la primacía masculina en la creatividad artística, pues identifica al autor con un hombre que es primario y a la mujer, producto de su creación, con un objeto pasivo y secundario que carece de autonomía. En esta tradición, el género femenino es el resultado de la imaginación masculina, por lo que no disfruta de una identidad y voz propias, $y$ la consecuencia es que se excluye a la mujer de la producción de la cultura. En el artículo, Luisa Molina no se presenta como una aficionada ni una imitadora de los logros masculinos en el campo de la literatura y en el terreno del pensamiento. Refiriéndose a la carta de la escritora guajira, que cita casi íntegramente en el ensayo, afirma: "Es imposible leer friamente las ingénuas y encantadoras lineas que acabamos de copiar, y que no pudieran ser imitadas por los primeros escritores del mundo" (1857: 10). En estas líneas, Gómez de Avellaneda no sólo saca a la escritora campesina del confinamiento de la mujer en el reino de principiante o en el ámbito de "amateur" en el cultivo de las letras, al colocarla a la par de los escritores universales más famosos; sino que aboga porque el género femenino obtenga el reconocimiento como un otro viable capaz de participar en el discurso poético en condiciones de igualdad en relación al varón. En su elogio a la carta de Luisa Molina, la escritora invalida el principio que sostiene que las mujeres son inferiores a los hombres en lo referente a la actividad creadora y además, insinúa que la mujer puede rivalizar en talento con el varón. Con el 
ejemplo de la poeta guajira, Gómez de Avellaneda invierte el drama del quehacer poético en el que usualmente es la escritora quien se enfrenta a la paradoja de internalizar el modelo de creación masculino; es decir, en el caso de Luisa Molina son los escritores, por el contrario, quienes deben de imitar su obra. Gómez de Avellaneda alienta a su compatriota a que cumpla su destino poético cuando declara "Tú eres poeta" de la tristeza y de la soledad según un designio divino, y de inmediato le exige: "Cumple tu destino, y canta" (1857: 10). La exhortación está dirigida, principalmente, a invitar a las mujeres a que se atrevan a aprender y a crear, es decir, a que ejerzan su derecho a disfrutar del placer del conocimiento y del goce creador, ya que el cultivo de las artes pertenece a todos por igual. Se trata de persuadir a las mujeres a que desarrollen sus facultades intelectuales y artísticas, y de brindarles apoyo, por un lado, en su audacia de transgredir la prohibición de que una mujer se convierta en autora e incluso que pueda llegar a ocupar la categoría de genio en las letras; y por otro, afirmar una perfectibilidad que es común para ambos sexos.

En este artículo, la escritora presenta a Luisa Molina como un sujeto creador y autónomo que no necesita de las obras masculinas para dar rienda suelta a su potencialidad creadora. Gómez de Avellaneda se vale de diversas estrategias retóricas para mostrar las exclusiones implícitas y explícitas a las que ha sido sometida la mujer en el eterno drama de la creación literaria, en específico en relación a la categoría del genio poético; y presenta los dilemas a los que se enfrentan las aspirantes a escritoras, esto es, aquellas mujeres que como Luisa Molina deciden apropiarse de la pluma y convertirse en poetas. La escritora subvierte la noción de que la creación artística es una labor exclusivamente masculina y se apropia del concepto de genio al afirmar que el talento excepcional es una capacidad espiritual innata de origen divino, lo cual no depende del sexo del sujeto. En el ensayo, Gertrudis Gómez de Avellaneda cita algunos fragmentos de los poemas de Luisa Molina, sobre los cuales emite el siguiente juicio: "Revélanse en todos ellos tanto ingenio y sentimiento como ignorancia del arte, $y$ hay, sobre todo, una sencillez y una espontaneidad encantadoras, que desarman completamente a la crítica" (1857:9). Como vemos, en su valoración de la obra poética de la escritora campesina destaca el estilo sencillo y espontáneo de sus versos y dicho gesto se constituye en una defensa en favor de una sensibilidad artística más libre y más auténtica que la racionalista. Dicho alegato en pro de la espontaneidad en el acto creativo está vinculado a una nueva categoría del genio poético que la escritora delinea en el ensayo, a la cual pueden aspirar aquellas mujeres que al igual que Luisa Molina, aunque nunca han recibido una educación formal, son autodidactas y muestran un talento singular.

En su artículo, Gómez de Avellaneda reproduce algunas estrofas que escoge de varios poemas de Luisa Molina, pero le dedica una mayor atención a la carta que la poeta campesina dirige a su amigo el Sr. D. Juan Roquero 
Domínguez. La escritora comenta que de lo poco que conoce de la obra de su compatriota, es precisamente este documento lo que considera más bello y original de toda su producción literaria (1857: 10). En la carta, Luisa Molina alude a los obstáculos y desventajas a que tienen que hacer frente las mujeres que como ella quieren cultivar su intelecto y dedicarse a las letras, e insinúa que todas tienen el derecho de acceder al estudio e instruirse, lo cual significaría para algunas la posibilidad de llegar a ser autoras y de expresar su genio. La poeta guajira se lamenta de no haber podido desarrollar un entendimiento más refinado y reconoce que el hecho de no haber tenido acceso a una educación continua y esmerada ha tenido repercusiones negativas en la calidad y profundidad de sus escritos. Con las siguientes palabras dirige una queja a su amigo, en la que subyace la idea de que leer y escribir son dos actividades idénticas, ya que se da un contagio de la lectura a la escritura: “¿Cómo le parece á usted que yo, sin ningun estudio que aclare mis ideas sobre innumerables cosas que ignore, pueda tener acierto para escribir?" (citado en Gómez de Avellaneda 1857: 10). En esta pregunta retórica, Luisa Molina deja implícito que el género femenino está condenado a la mediocridad, pero que con una buena educación el genio puede florecer en una mujer. De inmediato, la humilde poeta muestra una voluntad de saber, pues le confiesa a su interlocutor que quiere dedicarse de lleno al estudio, por lo que le ruega que le preste "una obra de filosofía" para el desarrollo y perfeccionamiento de su intelecto. Ella misma advierte: "Quisiera entender muchas cosas y no puedo alcanzarlas con mi entendimiento: quizá no sea esa ciencia la que me las enseñe; pero no importa, deseo verla...” (citado en Gómez de Avellaneda 1857: 10). La determinación de consagrarse al estudio para adquirir un alto grado de conocimiento y su intento de interpretar un texto filosófico indican que puede disfrutar de una obra fabricada por el intelecto y pensada por la razón; pero también la actividad de la lectura conduce directamente al acto de escribir, es decir, a producir un texto que transforma a la mujer que lee en autora. Por otro lado, el pedir prestado un libro de filosofía a un hombre es, ante todo, un gesto que reivindica el derecho que tiene la mujer a saber tanto y de la misma manera que el varón, a la vez que plantea una cuestión fundamental: la emancipación intelectual del sexo femenino que sólo es posible a través de la igualdad en el acceso al conocimiento, unido a la plena libertad en el uso de ese saber.

En la carta, Luisa Molina adopta una postura de aparente reconciliación con sus circunstancias adversas, esto es, tanto con las desventajas inherentes a su sexo como con su condición social de campesina ignorante y pobre que carece de recursos para dedicarse a revisar y publicar sus poemas. La escritora da la impresión de que está dispuesta a aceptar semejantes dificultades al asumir un papel secundario y limitado para su persona en el ámbito de las letras. No obstante, de inmediato revela a su benefactor que "no aspiro á alcanzar gloria, pero le temo al desprecio; y pienso muchas veces que yo, 
pobre mujer rústica, debo vivir siempre ignorada, bajo la sombra de mis azahares y de mi casi arruinada choza" (citado en Gómez de Avellaneda 1857: 10). Como se puede obsevar, la poeta guajira parece estar dispuesta a renunciar a su derecho al goce creador y a disfrutar de la celebridad literaria, pero insinúa que aspira a que su obra sea aceptada por el público lector y que reciba el mismo reconocimiento que los escritores masculinos.

Más adelante, la escritora desecha la pretensión de ser considerada un "genio poético" y de adjudicarse una autoridad literaria e intelectual, cuando declara en un tono de modestia: "La obra de perfeccionar los conocimientos humanos ha sido de muchos siglos y de centenares de genios eminentes y privilegiados. ¿Y qué persona habrá de las que escriben, que no tengan su imaginacion enriquecida con muchas ideas y variedad de estudios?" (citado en Gómez de Avellaneda 1857: 10). Por medio de esta interrogación retórica, Luisa Molina manifiesta su creencia de que todos los seres humanos, tanto hombres como mujeres, son perfectibles; pero dicha tesis implica que no puede haber una naturaleza genial sin educación, ya que el adquirir el conocimiento es lo que hace posible el perfeccionamiento del intelecto y el cultivo del talento artístico. En las líneas citadas, la poeta guajira emplea el tropo de auto-depreciación de la mujer escritora que, a pesar de considerarse a sí misma excepcional, simula que no aspira a que se reconozca su genialidad femenina. Luisa Molina sugiere que ella está dotada de una facultad innata para crear una gran obra de arte cuyo despliegue no tiene límites, lo cual es propio del sujeto genial; pero alega que ese talento natural no se puede desarrollar debido a la falta de acceso a la educación. Gómez de Avellaneda transcribe en el artículo la siguiente estrofa de una composición que la humilde poeta dedica "Al Sr. D. Juan Roquero Domínguez", uno de los bienhechores que anima a la joven campesina a que escriba sus versos:

No puedo espaciar mi pensamiento

Por los siglos que cita tu memoria, Ni enriquecer mi pobre entendimiento

Con los nobles periodos de la historia

Monótona cancion, sin sacro fuego,

Brota de un alma desmayada y triste,

(citado en Gómez de Avellaneda 1857: 10;

Molina, en Acosta y Blanchet 1856: 201-202).

En el mismo poema, la escritora guajira le dice a su amigo que conoce "De algunos vates los gloriosos nombres" y que incluso ha leído la "ilustre" obra poética de algunos de estos célebres autores (Molina, en Acosta y Blanchet 1856: 201). En los versos que siguen, la poeta establece un contraste entre la producción literaria de estos famosos bardos y su propia obra: se 


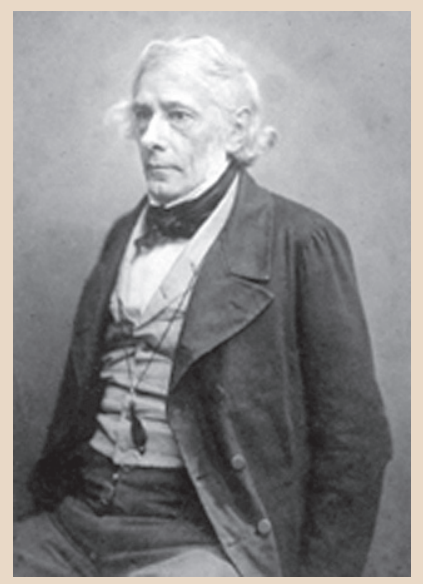

V. Cousin refiere a los poemas de los escritores masculinos como "canciones sublimes y armoniosas" de elocuente inspiración, mientras que según vimos antes, describe su poesía en el verso que dice "Monotona cancion, sin noble fuego," e insiste que no puede cantar "Con alta inspiracion" porque carece de estudios (Molina, en Acosta y Blanchet 1856: 201-202). Con esta comparación, Luisa Molina parece indicar que el delirio poético es posible en las mujeres, pero que en ellas no alcanza el alto grado e intensidad del viril delirio. La poeta se lamenta de su incapacidad para expresar y articular su locura divina, y de ahí que se sienta invadida por un sentimiento de impotencia vinculado al surgimiento de su voz lírica. Por último, llega a la conclusión de que sólo es capaz de ensayar "algun preludio" incompleto, dando a entender que el sitio que le está reservado en el campo de las letras es únicamente el de una "aficionada" o "principiante" que no puede elevarse a la categoría de una escritora profesional (Molina, en Acosta y Blanchet 1856: 202).

Gómez de Avellaneda también cita unos versos de un poema de su compatriota en los que afirma "la poetisa cubana pretende caracterizarse ella misma" (1857: 9). En su autofiguración poética, Luisa Molina se describe a sí misma en la línea que dice "Soy de la selva un rumor:" y más adelante reitera la debilidad de su voz lírica con las frases "solitario eco" y "doliente clamor"; $y$ finalmente alude a su persona como a una "humilde planta campestre" (citado en Gómez de Avellaneda 1857: 9; variante de esta estrofa en Molina, en Acosta y Blanchet 1856: 202). Como vemos, en estos versos la escritora presenta el dilema de la creatividad femenina de cómo configurar una voz propia que a la vez sea autónoma y fuerte, ya que el sometimiento a la autoridad masculina la vacía de espontaneidad y sofoca su impulso creador. Ante dicha situación, la poeta corre el riesgo de verse obligada a guardar silencio, es decir, a enmudecer, pues en los versos citados las referencias al "eco" y al "clamor" indican una pérdida paulatina de la voz y un debilitamiento de su potencia.

En su respuesta a la carta de Luisa Molina, la escritora elabora una versión del genio "femenino" en la que destaca el carácter innato y religioso de la inspiración lírica, pues presenta al artista, imitador de Dios, como un individuo que es guiado por el instinto divino en el acto creador de reproducir la belleza. En la definición de genio que aparece en el artículo que sirve de prospecto a la revista Album cubano, Gómez de Avellaneda resalta una vez más el origen divino del quehacer poético cuando declara: "El genio, ese don divino, ese poder misterioso que tiene por dominio el universo estético, cooperador de Dios en la produccion de lo bello, es lo mas grande, lo mas augusto, lo mas incomprensible que, despues de la Religion, existe sobre la tierra" (1860: 4). Por otro lado, las características que la escritora le adjudica al genio poético coinciden con la versión del concepto que formula Víctor Cousin (1792-1867) en sus escritos, la cual resulta fundamental en 
la valoración del Romanticismo español (Hernando 1995: 94). Gómez de Avellaneda concuerda con el filósofo francés en el atributo que distingue al genio del resto de los seres humanos: la potencia creadora a la que la escritora se refiere como un "poder misterioso" y que Cousin denomina un "no sé qué," esto es, una fuerza que inspira y atormenta al individuo de talento excepcional (Cousin 1867: 17). La escritora sigue la línea de pensamiento de Cousin que establece un estrecho vínculo entre el arte y la religión, pues para ambos la creación artística tiene un origen divino y de ahí que toda obra de arte tenga a Dios por principio y por fin (Gómez de Avellaneda 1860: 4). Según explica el filósofo, el arte es la reproducción libre de la belleza ideal que purifica y eleva el alma hacia el infinito, es decir, hacia la divinidad que "se nos manifiesta por la idea de la verdad, del bien y de la belleza" (Cousin 1867: 21). El filósofo sostiene que lo que anima al artista es el sentimiento exquisito de lo bello, y que el arte, al ser una manifestación de la belleza eterna, es en sí mismo moral y religioso (Cousin 1867: 22). Gómez de Avellaneda sigue de cerca los postulados de Cousin cuando declara que la facultad que posee el artista genial de "sentir y gozar la belleza", fuente de su inspiración, y de recrearlas bajo formas nuevas es un don otorgado por Dios (1857: 10).

En el artículo sobre Luisa Molina, Gómez de Avellaneda comparte una vertiente del pensamiento filosófico de Cousin, la idea de que existe un genio poético femenino, es decir, la noción de un tipo particular de genio poético que adjudica a ciertas mujeres dotadas de un talento excepcional. El pensador francés desarrolla el concepto de genio femenino en la obra monumental que inicia en los años 1840, titulada Etudes sur les femmes illustres et la societe du XVII siecle, donde recopila y da a conocer al público las cartas de varias damas ilustradas acompañadas de ensayos biográficos (Goldsmith 1989: 57). En el libro que dedica a la figura de Jacqueline Pascal como parte de esta empresa, el pensador francés establece una diferencia entre el hombre y la mujer que se dedican al cultivo de las letras, pero no aplica dicha distinción de género sexual al poeta, a quien considera un ser sagrado (Cousin 1845: 14). El filósofo prueba la existencia del genio femenino valiéndose de la figura de Jacqueline Pascal, a quien atribuye un don especial para la creación poética. Cousin describe a la joven como una mujer intelectual y apasionada dotada de la fuerza interior y el fervor del genio, y refiriéndose a su persona declara "celle d'une enfant pleine de génie" (1845: 24, 31). El filósofo comenta que de haber tenido acceso a una mayor cultura, Jacqueline se hubiera convertido en una figura que no admitiría límites ni comparación; lo cual a su vez sugiere que para Cousin la educación resulta un factor indispensable en el cultivo del talento (1845: 24). Una vez más, Gómez de Avellaneda comparte el pensamiento del filósofo, ya que en la carta de la poeta guajira que transcribe en el ensayo, la educación aparece como un elemento

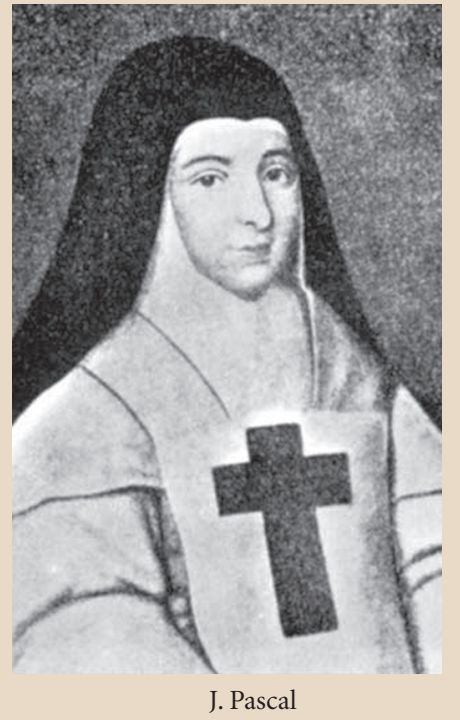

123 \begin{tabular}{||l} 
Atenea 490 \\
\cline { 2 - 2 }
\end{tabular} 
imprescindible para desarrollar la facultad intelectual de las mujeres y hacer posible la expresión de su genio individual en las artes. En torno a la comparación que hace entre esta singular figura femenina y su hermano Pascal, Cousin formula el principio de la igualdad del talento para ambos sexos así como el origen divino de la inspiración. Comenta respecto a Jacqueline Pascal: "Le ciel lui avait accordé tous les dons du génie avec les grâces de la femme. Elle n'était inférieure á son frère Pascal no par l'esprit ni par le caractère" (1845: 27).

En el artículo, Gómez de Avellaneda se apropia y al mismo tiempo se desvía del concepto romántico del genio para la mujer escritora, pues en la versión que ofrece del mismo no sólo incluye los rasgos distintivos del artista excepcional, sino que también introduce ciertas innovaciones en el término que resultan de gran relevancia para el género femenino. En la revisión que hace de la categoría de genio poético, la escritora se apoya en las doctrinas sobre la genialidad que elaboran Cousin y Kant como parte de sus teorías estéticas. Como hemos visto hasta ahora, el pensador francés ejerce una gran influencia en la definición del genio que Gómez de Avellaneda formula en el ensayo periodístico, pero también adopta el postulado del filosófo alemán que sostiene que el artista eminente posee una capacidad espiritual innata. En la Crítica del juicio, Kant sistematiza el concepto y define el genio como una facultad innata del espíritu mediante la cual la naturaleza brinda la regla del arte, y concluye que el arte bello sólo es posible como resultado de la genialidad artística. En la teoría kantiana, el genio es el producto de un acoplamiento entre la imaginación creadora y el intelecto; pero el pensador explica que consiste, de cierto modo, en la libre utilización de la facultad imaginativa, la cual ya no se encuentra sujeta a los vínculos y restricciones que impone el intelecto en el "uso cognoscitivo".

En su formulación del concepto de genio poético, la escritora coincide con el filósofo alemán en el carácter innato de la inspiración; pero va más allá al asumir una postura más radical que Kant en lo que concierne al papel que desempeña el intelecto en el proceso de la creación artística. Para Gómez de Avellaneda, el talento del genio está desvinculado del principio de la razón, pues alega que la inspiración del poeta o la poeta genial proviene de Dios y que el artista se percata de la belleza, en tanto vía de acceso a lo absoluto, a través de la intuición y de ahí que no dependa del conocimiento especulativo o de la razón teórica. La escritora emplea el tópico de la locura divina de los poetas para definir el fenómeno de la inspiración artística, en tanto un acontecimiento irracional que depende exclusivamente de la presencia divina que lo hace posible. Es decir, el entusiasmo, vigor y originalidad del genio poético proviene de una especie de fulgor divino que lo impele al acto creativo.

En el párrafo siguiente, Gómez de Avellaneda responde a las inquietudes 
que expresa Luisa Molina en su carta respecto a los dilemas que enfrenta la mujer escritora, y fundamenta su argumento que sostiene que la facultad creadora es un don natural otorgado por Dios, sin tomar en cuenta el género sexual, en la teoría de la locura divina de los poetas:

¿Qué falta te hacen los conocimientos especulativos, las contradictorias teorías, los flotantes sistemas de los hombres? Dios que convenció de locura, como dice admirablemente S. Pablo, a todo el saber humano, Dios solo hace al poeta, dándole privilegiadamente la preciosa facultad de sentir y gozar la belleza en todas sus relaciones y armonías; de inspirarse por ella y de reproducirla bajo formas nuevas y admirables, que no están sujetas al frio análisis ni á las deducciones del raciocinio. El poeta conoce por intuición cuanto es hermoso, grande, verdadero; $\mathrm{y}$ su mente divina es la misteriosa generadora de aquel gran mundo ideal [...] lenguaje que solo comprende el genio y que sólo él traduce. ¿¿Qué quieres aprender, pues, pobre Luisa? (1857: 10).

Curtius aclara que el tópico de la locura divina de los poetas, es decir, la idea de que el artista está inspirado por Dios, aparece expuesta por primera vez en el Fedro de Platón y se encuentra vinculada a la interpretación platónica de la doctrina de la inspiración y del entusiasmo. El crítico alega que la teoría de la "locura del poeta" en última instancia se deriva del concepto de la inspiración divina de la poesía, la cual a su vez se asocia al surgimiento de una conciencia esotérica del origen divino del acto poético (Curtius 1990: 667-668).

Por otro lado, en el comentario de Gómez de Avellaneda a la carta de la poeta guajira, la escritora reclama la autoridad de Pablo para probar la existencia del genio femenino, y defender la idea de que la mujer también posee la facultad divina del talento literario. La importancia del gesto retórico de citar al apóstol para sustentar su argumento, se puede entender mejor si tenemos en cuenta que Gómez de Avellaneda recupera uno de los principales postulados que aparece en los escritos paulinos: la igualdad de todos los seres humanos, sin distinción de género sexual, raza u origen social, ante la presencia de Dios. La interpretación tradicional de las cartas de San Pablo intentaba borrar el protagonismo de la mujer y su colaboración en igualdad con los varones, en el origen y propagación del cristianismo. Sin embargo, en las epístolas paulinas las mujeres aparecen activas, participando y ejerciendo funciones misioneras, de enseñanza y de liderazgo en las comunidades (Bernabé 1993: 44). En la primera Carta a los Corintios, el apóstol aborda el tema de la relación entre los sexos y el papel que le corresponde desempeñar al género femenino en la sociedad. En lo que concierne al matrimonio, Pablo lo concibe como una relación de reciprocidad e igualdad entre mujer y varón, asumiendo un igualitarismo radical, pues aboga por la igualdad en las obligaciones de los esposos y en que cada uno de los cónyuges ejerza una 
autoridad mutua sobre el otro (1 Cor 7, 3-5, 10-11-12.16). Por lo tanto se podría decir que hay indicaciones en los escritos del apóstol de una transformación en las relaciones entre los sexos, ya que la forma usual en que se entendían las relaciones jerárquicas entre mujer y hombre han sido modificadas como anticipación del reino de Dios (1 Cor 7: 3-4; Gal 3:28).

Precisamente lo que rescata Gómez de Avellaneda del corpus paulino, al recordar la frase del apóstol de que "Dios convenció de locura a todo el saber humano," es la abolición de la diferencia sexual por medio de la fe. La sentencia paulina representa un alegato en favor de la razón de la humanidad en general, y por consiguiente, comprende a los dos sexos no excluyendo a la mujer de la esfera de la razón. Al legitimar su argumento sobre el origen divino del genio poético con la cita de San Pablo, la escritora aborda la cuestión de la relación entre el género sexual y la facultad de la razón. Gómez de Avellaneda deja implícito que hay que rechazar la creencia de la influencia del sexo sobre las cualidades intelectuales. De acuerdo a la escritora que se apoya en la autoridad del apóstol, el intelecto es neutro y no tiene sexo, mientras que el saber razonar es un acto de libertad individual que simboliza la dignidad humana. Es decir, si se eliminan las trabas a la educación de las mujeres, su ser intelectual es absolutamente idéntico al del varón. Para Gómez de Avellaneda, se debe establecer la igualdad entre los sexos en el ejercicio de la razón, porque ésta es una facultad propia de todo ser humano, hombre o mujer, y de ahí que insinúe en su respuesta a la carta de Luisa Molina que las mujeres no sólo pueden hacer uso de su intelecto, sino que además son capaces de desplegar una facultad intelectual y un talento artístico que no tiene límites. A partir de la premisa de la igualdad cristiana, la escritora deja implícito que tanto el varón como la mujer están dotados de las mismas facultades, y por lo tanto, no hace distinción de género sexual. Por otro lado, el apóstol declara en la carta a los Gálatas que no hay ni hombre ni mujer, pues todos son uno en Jesucristo (Gálatas 3:28). Dicha fórmula bautismal invocada por Pablo se halla en el centro de la filosofía cristiana, siendo la democracia de las almas un dogma central de la fe: todos los cristianos, sin tomar en cuenta el género sexual, están unidos en la figura de Cristo por la fe. Por lo tanto, el cristianismo es la única de las religiones universales que proclama la igualdad de los sexos, ya que anula la distinción entre hombre y mujer ante los ojos de Dios. La fórmula bautismal del apóstol borra las oposiciones binarias e implica una disolución radical de las diferencias sexuales que se construyen socialmente.

Gómez de Avellaneda establece un paralelismo entre tres figuras femeninas, las cuales tienen en común el haber podido trascender con su excepcional talento la condición adversa de ser mujeres campesinas, humildes e ignorantes: Luisa Molina, la ciega de Manzanares y Juana de Arco. En el siguiente fragmento se detiene en la comparación que hace entre la escritora cubana y la heroína francesa: 
Luisa Molina ha escuchado tambien desde sus primeros años, y entre las asperas faenas del campo, esas intimaciones irresistibles de la inspiracion y el entusiasmo, que en balde intentarían sofocar la voluntad y el raciocinio. Como los ángeles belicosos, que descendían de las esferas azuladas para poner en la mano femenil de la pastorcilla de Orleáns el sagrado acero de la patria, gritándole: -¡Tú serás su salvadora!, asi ha contemplado tambien la joven campesina del Moreto , bajar resplandecientes á su humilde cabaña las divinas visiones del mundo de las ideas, trayéndole la lira y anunciándole con inefables acentos - itu serás poeta! Y Luisa cumple la estraña profecia: Luisa es poeta, como fue Juana héroe; pues no es dado al hombre eludir jamás los decretos del destino, ni nada alcanza á desviar la fatal aureola de aquellas frentes marcadas por la Providencia con el doble sello del infortunio y del genio (1857: 9).

En la comparación que hace la escritora entre Luisa Molina, poeta de la lira, y Juana de Arco, heroína de la espada, subyace el tópico de las "armas y las letras," recurrente en la literatura española del Siglo de Oro; y que posteriormente se sustituye en el romanticismo francés por la fórmula de "pluma y espada" (Curtius 1990: 257-58). Gómez de Avellaneda se vale de estas dos figuras ejemplares para dejar abierta la posibilidad de que surga un tipo de genio femenino que sea todo a la vez: mujer de letras y además, que preste servicios militares, es decir, que sea posible fundir la vida artística con la vida guerrera en la figura de la poeta-soldado; reminiscente de grandes autores como Garcilaso de la Vega y Alonso de Ercilla, para sólo mencionar algunos. Esta versión del genio femenino que perfila la escritora reúne en sí misma las “armas y las letras," y amplía el problema de la genialidad artística al reinscribir los dos elementos del tópico, la pluma y la espada, en el campo más vasto del derecho de las mujeres a acceder a todo lo que un hombre puede ser (autor y soldado) y hacer (escribir y combatir). Por consiguiente, Gómez de Avellaneda coloca la cuestión esencial de la existencia o inexistencia del genio femenino, como el punto donde se juega la absoluta igualdad de los sexos.

En el pasaje citado arriba, la escritora cuestiona el sistema que asigna determinados instrumentos de producción a cada sexo; en particular, en lo que se refiere a la espada y la pluma, utensilios en apariencia poco aptos para la mano de una dama. En este sistema de distribución, se le atribuye a cada sexo las armas y los instrumentos de acuerdo a sus respectivos talentos. Por lo tanto, al varón considerado apto para la actividad creadora del genio se le otorgan la espada y la pluma, mientras que al género femenino le corresponden aquellas herramientas que resultan adecuadas al sexo del sentimiento y del corazón: la aguja y el huso. Gómez de Avellaneda se apodera para la mujer de los instrumentos que se convierten en emblemas de la supremacía y del poder masculino, la espada y la pluma, a través de las figuras de Juana de Arco y Luisa Molina. La escritora coloca en "la mano femenil"

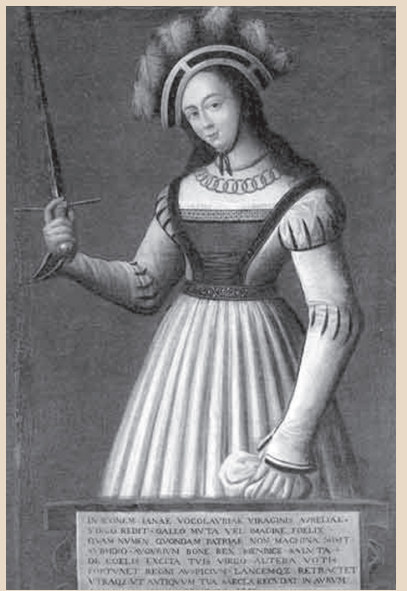

J. de Arco 
de la heroína francesa "el sagrado acero de la patria," reivindicando el derecho del género femenino a luchar en el campo de batalla. Por otro lado, a la poeta guajira le adjudica la lira, que al ser el instrumento de música de Orfeo y símbolo de los poetas evoca la pluma y la actividad de la escritura. De ahora en adelante el acto de escribir y de combatir se convierten en actividades adecuadas y legítimas para el género femenino, a la vez que se anula la creencia de que cada sexo se distingue del otro, no sólo en las armas e instrumentos que le pertenecen, sino también en sus talentos.

Por otra parte, en la imagen de Juana de Arco como doncella armada que dirigía las tropas francesas en el campo de batalla se conjugan el valor y la fuerza (Warner 1981: 15). En otras palabras, la figura de una doncella guerrera que con sus hazañas demostró un heroísmo indomable, encarna todas las posibilidades de la excelencia femenina, pues en ella se conjugan la virtud, la razón, la fuerza física y el coraje. Esta heroína disfrazada de hombre decide abandonar la casa paterna y transformarse ella misma en caballero para cumplir su destino (Warner 1981: 156). Por lo tanto, Juana de Arco es la personificación de la movilidad y de una autonomía fiera, porque no aceptó ni su origen campesino y humilde, ni su condición femenina, es decir, rechazó las limitaciones que la sociedad le había impuesto a su sexo. El travestismo de Juana de Arco, es decir, el tomar prestado el atuendo varonil, constituye una estrategia vital de cambio, pues la doncella armada podía trascender su condición de mujer liberándose de las ataduras impuestas al género femenino; $y$ al hacerlo, usurpar los privilegios masculinos e incluso reclamar una grandeza que iba más allá del potencial esperado de su sexo.

En el artículo, Gómez de Avellaneda establece las semejanzas que unen a estas dos figuras ejemplares pertenecientes a épocas distintas: ambas son inocentes jóvenes llamadas por Dios para cumplir su singular destino: una ser poeta, la otra soldado y heroína de la nación. Además, tanto Juana de Arco como Luisa Molina permanecen cercanas a la naturaleza, fuente de su inspiración, pero quizás el punto en común que más une a estas dos figuras excepcionales es el origen sobrenatural de las voces, signo divino que le anuncia a cada una el contenido de su misión. Gómez de Avellaneda le sugiere a Luisa Molina que al igual que la heroína francesa se entregue al mensaje que le comunican sus "visiones del mundo de las ideas", signo providencial del destino poético que está llamada a cumplir (1857: 9).

Por otro lado, la otra figura femenina con que Gómez de Avellaneda compara a la escritora campesina es María Francisca Diez Carralero, una poeta ciega de fecunda imaginación, que vivía en La Mancha, un pueblo árido de Manzanares localizado en Granada. En el artículo, la escritora cuenta cómo tuvo la oportunidad de pasar por el pueblo de Manzanares, donde conoció a "una muchacha ciega, que pedia limosna en sentidos, aunque desaliñados versos, improvisados por ella con asombrosa facilidad. Y bien: Luisa Molina 
es como la ciega de Manzanares, una naturaleza inculta, una pobre niña del pueblo, que ha nacido y que vive todavia bajo el pajizo techo de una choza" (1857: 9).

El paralelismo que establece Gómez de Avellaneda entre estas tres figuras femeninas (Luisa Molina, La ciega de Manzanares y Juana de Arco) es una estrategia retórica, cuyo objetivo es eliminar el prejuicio de la inferioridad de las mujeres en su fuerza física a través de las hazañas de la heroína francesa; y refutar la creencia de que el género femenino es inferior al varón en el alma y en el intelecto, pues todas son mujeres virtuosas que muestran una inteligencia innata sin haber recibido una educación formal. Por lo tanto, Gómez de Avellaneda parece querer decir al lector con el ejemplo de estas figuras femeninas, que las mujeres pueden elevarse a la misma altura que los hombres extraordinarios e incluso llegar a sobrepasarlos. Por otra parte, a través de estas tres mujeres excepcionales, la escritora prueba la existencia del genio natural femenino, al mismo tiempo que vincula la genialidad con el infortunio, uno de los rasgos típicos del genio.

Para concluir, hemos visto cómo en este artículo Gertrudis Gómez de Avellaneda recupera el concepto de genio para las mujeres a través de la figura desconocida de Luisa Molina. La escritora legitima y confiere autoridad a la poeta guajira basándose en la idea de la inspiración divina del genio poético, y en la premisa de la igualdad cristiana que expone San Pablo en sus epístolas, la cual se extiende al saber y al talento del género femenino. De ahí que Gómez de Avellaneda confiera la máxima autoridad a Luisa Molina, pues se apoya en un poder que supera lo humano y que además anula la diferencia entre los sexos.

\section{REFERENCIAS}

Acosta, Ignacio María de, Emilio Blanchet (eds.). 1856. Aguinaldo de Luisa Molina. Matanzas: Imprenta y Papelería La Aurora.

Albin, María C. 2004. "El cristianismo y la nueva imagen de la mujer: la figura histórica de María en los ensayos de Gómez de Avellaneda”, en Perspectivas trasatlánticas. Estudios coloniales hispanoamericanos. Ed. Raúl Marrero-Fente. Madrid: Verbum, pp. 315-353.

2002. Género, poesía y esfera pública. Gertrudis Gómez de Avellaneda y la tradición romántica, Madrid: Trotta, pp. 169-200.

2000. "Fronteras de género, nación y ciudadanía: La Ilustración.

Album de las Damas (1845) de Gertrudis Gómez de Avellaneda". Actas del XIII Congreso de la Asociación Internacional de Hispanistas, Madrid: Castalia, pp. 6775 .

. 1995. “Album cubano de Gertrudis Gómez de Avellaneda: La esfera pública y la crítica a la modernidad”. Cincinnati Romance Review 14, pp. 73-79. 
Arias, Salvador (dir.). 2002. Historia de la literatura cubana. Instituto de Literatura y Lingüística. Tomo I. La Habana: Editorial Letras Cubanas, pp. 269-274.

Bernabé, Carmen. 1993. "Biblia”, en 10 mujeres escriben teología. Ed. de Mercedes Navarro. Navarra: Editorial Verbo Divino, pp. 13-62.

Battersby, Christine. 1990 [1989]. Gender and genius: Toward a feminist aesthetics. Bloomington: Indiana University Press.

Biblia. 1989. Madrid: Paulinas y Verbo Divino.

Carbonell y Rivero, José Manuel. 1928. La poesía lírica en Cuba. Tomo III. La Habana: Imprenta El Siglo XX.

Cortés, José Domingo (editor). 1896. Poetisas americanas. Ramillete poético del bello sexo hispano-americano. París: Librería de la Vda. de Ch. Bouret.

Cousin, Víctor. 1867. Breve tratado sobre lo bello. Trad. de M. E. Madrid: Almacén Música y fábrica de pianos del editor B. Esclava. 1845. Jacqueline Pascal. Paris, Didier, Libraire-Editeur.

Curtius, Robert Ernst. 1990 [1953]. European Literature and the Latin Middle Ages. New Jersey: Princeton University Press.

Fornaris, José, Joaquín Lorenzo Luaces (compiladores). 1861. Cuba poética. Colección escogida de las composiciones en verso de los poetas cubanos desde Zequeira hasta nuestros días. La Habana: Imprenta de la viuda de Barcina y Comp.

Geneviè, Fraisse. 1991 [1989]. Musa de la razón: La democracia excluyente y la diferencia de los sexos. Madrid: Ediciones Cátedra.

Goldsmith, Elizabeth C. 1989. "Authority, Authenticity, and the Publication of Letters by Women", en Writing the Female Voice: Essays on Epistolary Literature. Boston: Northeastern University Press, pp. 46-59.

Gómez de Avellaneda, Gertrudis. 1857. “Luisa Molina”, en La América 6, 24 de mayo, pp. 9-10.

.1860. Album cubano de lo bueno y de lo bello: Revista quincenal, de moral, literatura, bellas artes y modas. La Habana: Imprenta del Gobierno y Capitanía General por S. M.

González Curquejo, Antonio (recopilación). 1913. Florilegio de escritoras cubanas. Tomo II. La Habana: Aurelio Miranda Impresor.

Hernando, Javier. 1995. El pensamiento romántico y el arte en España. Madrid: Ediciones Cátedra, pp. 89-110.

León, Rogelia. 1864. “La ciega de Manzanares”, en La Violeta año II, núm. 82, 26 de junio, Madrid, pp. 5-7.

Milanés, Federico. 1856. "Miscelánea. Un pensamiento sobre la señorita doña Luisa Molina”, en Revista de la Habana $2^{a}$ serie, 1. 15 de octubre. La Habana: Imprenta del Tiempo, pp. 125-28.

Warner, Marina. 1981. Joan of Arc: The Image of Female Heroism. New York: Alfred A. Knopf.

Zenea, Juan Clemente. 1852. "Una poetisa matancera”, en El Almendares, tomo I, marzo 28. La Habana: Imprenta del Tiempo, pp. 173-76.

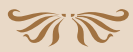

Atenea 490 